\title{
Correction: Benchmarking of survival outcomes following haematopoietic stem cell transplantation: A review of existing processes and the introduction of an international system from the European Society for Blood and Marrow Transplantation (EBMT) and the Joint Accreditation Committee of ISCT and EBMT (JACIE)
}

John A. Snowden $\mathbb{1}^{1} \cdot$ Riccardo Saccardi $^{2} \cdot$ Kim Orchard $^{3} \cdot$ Per Ljungman $\mathbb{1}^{4} \cdot$ Rafael F. Duarte $^{5} \cdot$ Myriam Labopin $^{6} \cdot$ Eoin McGrath $\mathbb{1}^{7} \cdot$ Nigel Brook $^{8} \cdot$ Carmen Ruiz de Elvira $^{8} \cdot$ Debra Gordon $^{8} \cdot$ Hélène A. Poirel $\mathbb{D}^{9} \cdot$ Francis Ayuk $^{10}$.

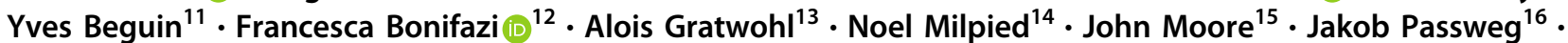
J. Douglas Rizzo ${ }^{17}$ - Stephen R. Spellman ${ }^{18}$ - Jorge Sierra ${ }^{19}$. Carlos Solano $^{20}$ • Fermin Sanchez-Guijo ${ }^{21}$. Nina Worel ${ }^{22}$ - Andreu Gusi ${ }^{7}$ - Gillian Adams ${ }^{7}$. Theodor Balan ${ }^{23} \cdot$ Helen Baldomero $^{16}$ - Gilles Macq ${ }^{9}$. Evelyne Marry ${ }^{24}$. Florence Mesnil ${ }^{24}$ - Elena Oldani ${ }^{25} \cdot$ Rachel Pearce $^{26}$ - Julia Perry ${ }^{26}$ - Nicole Raus ${ }^{27}$. Urs Schanz ${ }^{28}$.

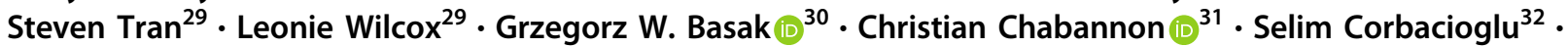
Harry Dolstra ${ }^{33} \cdot$ Jürgen Kuball $^{34} \cdot$ Mohamad Mohty $^{35}$ - Arjan Lankester $^{36} \cdot$ Sylvia Montoto $^{37}$ - Arnon Nagler $^{38}$. Jan Styczynski ${ }^{39} \cdot$ Ibrahim Yakoub-Agha $^{40} \cdot$ Regis Peffault de Latour ${ }^{41} \cdot$ Nicolaus Kroeger $^{10} \cdot$ Ronald Brand $^{23}$. Liesbeth C. de Wreede ${ }^{23} \cdot{\text { Erik van } \text { Zwet }^{23} \cdot \text { Hein Putter }}^{23}$

Published online: 21 November 2019

(c) The Author(s) 2019. This article is published with open access

\section{Correction to: Bone Marrow Transplantation} https://doi.org/10.1038/s41409-019-0718-7

Following publication, it was noted that some author names were misspelt. Jan Styczinski has been corrected to Jan Styczynski, Regis Peffault de la Tour has been corrected to Regis Peffault de Latour and Gzregorz Basak has been corrected to Grzegorz W. Basak. This has been updated in the HTML and PDF versions of this article.
John A. Snowden

john.snowden1@nhs.net

Extended author information available on the last page of the article
Open Access This article is licensed under a Creative Commons Attribution 4.0 International License, which permits use, sharing, adaptation, distribution and reproduction in any medium or format, as long as you give appropriate credit to the original author(s) and the source, provide a link to the Creative Commons license, and indicate if changes were made. The images or other third party material in this article are included in the article's Creative Commons license, unless indicated otherwise in a credit line to the material. If material is not included in the article's Creative Commons license and your intended use is not permitted by statutory regulation or exceeds the permitted use, you will need to obtain permission directly from the copyright holder. To view a copy of this license, visit http://creativecommons. org/licenses/by/4.0/. 


\section{Affiliations}

John A. Snowden $\mathbb{D}^{1} \cdot$ Riccardo Saccardi $^{2} \cdot$ Kim Orchard $^{3} \cdot$ Per Ljungman $\mathbb{1}^{4} \cdot$ Rafael F. Duarte $^{5} \cdot$ Myriam Labopin $^{6} \cdot$ Eoin McGrath $\mathbb{1}^{7} \cdot$ Nigel Brook ${ }^{8}$. Carmen Ruiz de Elvira ${ }^{8} \cdot$ Debra Gordon $^{8} \cdot$ Hélène A. Poirel $\mathbb{D}^{9} \cdot$ Francis Ayuk $^{10}$. Yves Beguin ${ }^{11}$. Francesca Bonifazi $\mathbb{I}^{12}$. Alois Gratwohl ${ }^{13} \cdot$ Noel Milpied $^{14} \cdot$ John Moore $^{15} \cdot$ Jakob Passweg $^{16}$. J. Douglas Rizzo ${ }^{17}$. Stephen R. Spellman ${ }^{18}$. Jorge Sierra ${ }^{19}$. Carlos Solano ${ }^{20}$ • Fermin Sanchez-Guijo ${ }^{21}$. Nina Worel ${ }^{22} \cdot$ Andreu Gusi $^{7} \cdot$ Gillian Adams ${ }^{7} \cdot$ Theodor Balan $^{23} \cdot$ Helen Baldomero $^{16}$ - Gilles Macq ${ }^{9}$. Evelyne Marry $^{24}$ - Florence Mesnil ${ }^{24}$ - Elena Oldani ${ }^{25} \cdot$ Rachel Pearce $^{26}$ - Julia Perry ${ }^{26}$ - Nicole Raus ${ }^{27}$. Urs Schanz ${ }^{28}$. Steven $\operatorname{Tran}^{29} \cdot$ Leonie Wilcox $^{29} \cdot{\text { Grzegorz W. Basak } \mathbb{D}^{30} \cdot \text { Christian Chabannon }^{31} \text { - Selim Corbacioglu }}^{32}$. Harry Dolstra ${ }^{33}$ - Jürgen Kuball ${ }^{34} \cdot$ Mohamad Mohty $^{35}$ - Arjan Lankester $^{36}$. Sylvia Montoto ${ }^{37}$ - Arnon Nagler $^{38}$. Jan Styczynski ${ }^{39} \cdot$ Ibrahim Yakoub-Agha $^{40} \cdot$ Regis Peffault de Latour $^{41} \cdot$ Nicolaus Kroeger $^{10} \cdot$ Ronald Brand $^{23}$.

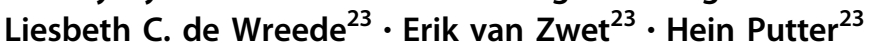

1 Department of Haematology, Sheffield Teaching Hospitals NHS Foundation Trust, Sheffield, UK

2 Haematology Department, Careggi University Hospital, Florence, Italy

3 Department of Haematology, Southampton General Hospital, Southampton, UK

4 Department of Cellular Therapy and Allogeneic Stem Cell Transplantation, Karolinska University Hospital, Division of Hematology, Department of Medicine Huddinge, Karolinska Institutet, Stockholm, Sweden

5 Servicio de Hematologia y Hemoterapia, Hospital Universitario Puerta de Hierro Majadahonda, Madrid, Spain

6 EBMT Study Office, Hôpital Saint Antoine, Paris, France

7 EBMT Executive Office, Barcelona, Spain

8 EBMT Registry Office, London, UK

9 Belgian Cancer Registry, Brussels, Belgium

10 Department of Stem Cell Transplantation, University Medical Center Hamburg, Hamburg, Germany

11 Department of Haematology, CHU and University of Liège, Liège, Belgium

12 Institute of Hematology "Seràgnoli", S. Orsola-Malpighi University Hospital, Bologna, Italy

13 Department of Hematology, Medical Faculty, University of Basel, Basel, Switzerland

14 CHU Bordeaux, service d'hematologie et therapie Cellulaire, F33000 Bordeaux, France

15 Department of Haematology, St Vincent's Hospital Sydney, Darlinghurst, NSW, Australia

16 EBMT Activity Survey office and Swiss National Transplant Registry SBST, Basel University Hospital, Switzerland, Basel, Switzerland

17 Center for International Blood and Marrow Transplant Research, Milwaukee, WI, USA

18 Center for International Blood and Marrow Transplant Research, Minneapolis, MN, USA

19 Hematology Department, Hospital Sant Pau, Barcelona, Spain
20 Servicio de Hematología, Hospital Clínico de Valencia, Valencia, Spain

21 IBSAL, Hospital Universitario de Salamanca, Salamanca, Spain

22 Blood Group Serology and Transfusion Medicine, Medical University of Vienna, Vienna, Austria

23 Department of Biomedical Data Sciences, Leiden University Medical Center, Leiden, The Netherlands

24 Agence de la biomédecine, Paris, France

25 Italian National BMT Registry (GITMO), Bergamo, Italy

26 BSBMT Data Registry, London, UK

27 Société Francophone de Greffe de Moelle et de Thérapie Cellulaire (SFGM-TC) Centre Hospitalier Lyon Sud, Pierre-Bénite, France

28 Haematology, University Hospital, Zurich, Switzerland

29 Australasian Bone Marrow Transplant Recipient Registry (ABMTRR), Darlinghurst, NSW, Australia

30 Department of Hematology, Oncology and Internal Medicine, Medical University of Warsaw, Warsaw, Poland

31 Institut Paoli Calmettes \& Centre d'Investigations Cliniques en Biothérapies, Marseille, France

32 Department of Pediatric Hematology, Oncology and Stem Cell Transplantation, University of Regensburg, Regensburg, Germany

33 Department of Laboratory Medicine, Radboud UniversityNijmegen Medical Centre, Nijmegen, The Netherlands

34 Department of Haematology, University Medical Center Utrecht, Utrecht, The Netherlands

35 Service d'Hematologie Clinique, Saint-Antoine Hospital, AP-HP, Sorbonne University, and INSERM UMRs 938, Paris, France

36 BMT Centre, Leiden University Hospital, Leiden, The Netherlands

37 St. Bartholomew's and The Royal London NHS Trust, London, UK

38 Chaim Sheva Medical Center, Tel-Hashomer, Israel

39 Collegium Medicum, Nicolaus Copernicus University, Bydgoszcz, Poland

40 CHU de Lille, Université de Lille, Lille, France

41 Saint Louis Hospital, Paris Diderot University, Paris, France 